\title{
Reduced Circumferential Resection Margin Involvement in Rectal Cancer Surgery: Results of the Dutch Surgical Colorectal Audit
}

\author{
Lieke Gietelink, MD; ; Michel W.J.M. Wouters, PhDa,b; Pieter J. Tanis, PhDc; Marion M. Deken, MD'; \\ Martijn G. ten Berge, MDa ; Rob A.E.M. Tollenaar, MD, PhDa ; J. Han van Krieken, MD, PhD ; and \\ Mirre E. de Noo, PhD'; on behalf of the Dutch Surgical Colorectal Cancer Audit Group
}

\section{Abstract}

Background: The circumferential resection margin (CRM) is a significant prognostic factor for local recurrence, distant metastasis, and survival after rectal cancer surgery. Therefore, availability of this parameter is essential. Although the Dutch total mesorectal excision trial raised awareness about CRM in the late 1990s, quality assurance on pathologic reporting was not available until the Dutch Surgical Colorectal Audit (DSCA) started in 2009. The present study describes the rates of CRM reporting and involvement since the start of the DSCA and analyzes whether improvement of these parameters can be attributed to the audit. Methods: Data from the DSCA (2009-2013) were analyzed. Reporting of CRM and CRM involvement was plotted for successive years, and variations of these parameters were analyzed in a funnelplot. Predictors of CRM involvement were determined in univariable analysis and the independent influence of year of registration on CRM involvement was analyzed in multivariable analysis. Results: A total of 12,669 patients were included for analysis. The mean percentage of patients with a reported CRM increased from $52.7 \%$ to $94.2 \%$ (2009-2013) and interhospital variation decreased. The percentage of patients with CRM involvement decreased from $14.2 \%$ to $5.6 \%$. In multivariable analysis, the year of DSCA registration remained a significant predictor of CRM involvement. Conclusions: After the introduction of the DSCA, a dramatic improvement in CRM reporting and a major decrease of CRM involvement after rectal cancer surgery have occurred. This study suggests that a national quality assurance program has been the driving force behind these achievements. (J Natl Compr Canc Netw 2015;13:1111-1119)

\section{Background}

Surgical resection remains the cornerstone of curative treatment in rectal cancer. ${ }^{1}$ The implementation and standardization of the total mesorectal excision (TME) technique and the introduction of preoperative (chemo)radiotherapy have led to improved oncologic outcomes. 2,3 The circumferential resection margin (CRM) indicates the distance from the tumor to the resection plane in a transverse section through the TME specimen. Tumor-negative noninvolved CRM is defined as the absence of microscopic tumor cells within $1 \mathrm{~mm}$ of

\footnotetext{
From the aDepartment of Surgery, Leiden University Medical Center, Leiden; 'bepartment of Surgical Oncology, Netherlands Cancer Institute-Antoni van Leeuwenhoek, Amsterdam; 'Department of Surgery, Academic Medical Center, Amsterdam; dDepartment of Surgery, Deventer Hospital, Deventer; and eDepartment of Pathology, Radboud University Medical Center, Nijmegen, The Netherlands.

Submitted April 16, 2015; accepted for publication July 23, 2015. The authors have disclosed that they have no financial interests, arrangements, affiliations, or commercial interests with the manufacturers of any products discussed in this article or their competitors.

Correspondence: Lieke Gietelink, MD, Department of Surgery, Leiden University Medical Center, Albinusdreef 2, 2333 ZA, Leiden, The Netherlands. E-mail: I.gietelink@lumc.nl
}

the inked resection margin. This is the most significant prognostic factor for local recurrence, distant metastasis, and survival after rectal cancer surgery. ${ }^{4}$ Therefore this parameter provides important information on both the quality of surgical resection and the prognosis of the patient.

Because of its prognostic value, the CRM has been frequently used as a surrogate end point in randomized controlled trials. ${ }^{5,6}$ In The Netherlands, a standard pathology protocol to examine a TME specimen was introduced in the 1990s, related to the start of the Dutch TME trial. ${ }^{5}$ Because of this standardization, $97 \%$ of patients included in this trial had a reported CRM. ${ }^{2}$ In subsequent years, until the start of the Dutch Surgical Colorectal Audit (DSCA) in 2009, there was no national quality assurance on histopathologic reporting, and the CRM was presumably less frequently reported in routine practice outside a trial setting.

The DSCA evaluates and reports on the quality of care of primary colorectal cancer surgery. ${ }^{7}$ It provides periodic feedback to all hospitals in The Netherlands on a set of quality measures, including 2 indicators regarding the CRM in rectal cancer surgery. The objective of this 
study was to evaluate the rates of CRM reporting and involvement throughout the successive years of the DSCA registration. Secondly, it analyzes changes in these CRM-related quality indicators over time and investigates the potential contribution of the DSCA to observe changes in a multivariable model.

\section{Methods}

Data were derived from the DSCA, a disease-specific national audit. This audit collects information on patient, tumor, treatment, and outcome characteristics and contains data on approximately $97 \%$ of all patients who underwent a resection for primary colorectal carcinoma in The Netherlands. ${ }^{8}$ The data set is based on evidence-based guidelines and compared on a yearly basis with the data registered in the Netherlands Cancer Registry (NCR). Details of this data set regarding data collection and methodology have been published previously. ${ }^{7,9}$

\section{Patients}

For this study, no ethical approval or informed consent was required under Dutch law. All patients $(\mathrm{N}=13,029)$ undergoing surgical resection for primary rectal cancer between January 1, 2009, and December 31, 2013, and registered in the DSCA before March 15, 2014, were evaluated. Patients with multiple synchronous tumors with at least 1 tumor located in the rectum were included. Patients who underwent a local excision with or without completion TME surgery were excluded $(n=241)$. Patients with a complete pathologic response (ypT0) on neoadjuvant (chemo)radiotherapy were also excluded $(n=610)$. Minimal data requirements to consider a patient eligible for analyzes were information on tumor location and date of surgery. Baseline characteristics of the study population and treatment characteristics are displayed per year in Table 1.

\section{Circumferential Resection Margin}

The mean percentage of reported CRM and the reported CRM rate per hospital for each year of the study period were calculated. The CRM was considered positive if tumor cells were present within $1 \mathrm{~mm}$ from the inked margin according to the definition of the Dutch guideline. ${ }^{10} \mathrm{CRM}$ involvement was only calculated for patients with a reported CRM. The mean percentage of CRM involvement and the percentage of CRM involvement per hospital were calculated for each year.

\section{Statistical Analyses}

Differences in baseline characteristics between different years of the study period were analyzed using a chi-square test. A P value of less than .05 was considered statistically significant. Potential predictors of CRM involvement were determined in a univariable analysis. Variables with a significance level of $P$ less than .10 in univariable analysis were subsequently included in a multivariable logistic regression model as categorical variables. To analyze the possible effect of the DSCA on CRM involvement, the year of DSCA registration was added as an ordinal variable to the multivariable model. A scatterplot with each dot representing an individual hospital was used to visualize the hospital variation in CRM reporting for the years 2009, 2011, and 2013. The number of patients who underwent a resection for rectal cancer is plotted on the $x$ axis and the percentage of patients with a reported CRM on the $y$ axis. The overall mean percentage is represented as a horizontal line.

A funnel plot was used to visualize the hospital variation in case-mix-corrected CRM involvement for the years 2009, 2011, and 2013. Variables included in this case-mix correction for CRM involvement included type of resection, laparoscopic resection, emergency surgery, and pathologic T classification. The number of patients with a reported CRM is plotted on the $x$ axis and the percentage of CRM involvement on the $y$ axis. The overall average CRM involvement is represented by a horizontal line with its $95 \%$ and $99 \%$ confidence limits, based on a Poisson distribution, varying in relation to the population size of each hospital. To evaluate the linear effect of year of registration on CRM involvement, we performed a linear-by-linear association test. Statistical analyzes were performed in PASW Statistics, version 20 (SPSS Inc., Chicago, IL).

\section{Results}

\section{Patient and Treatment Characteristics}

A total of 12,178 patients, registered by 91 hospitals, were included for analysis. Patient, tumor, and treatment characteristics are displayed in Table 1. A decrease occurred in unspecified clinical $T$ classification $(P<.001)$. The use of MRI as preoperative imaging technique increased $(P<.001)$ and so $\mathrm{did}$ the percentage of patients who were preoperatively discussed in a multidisciplinary team (MDT) meet- 
Reduced Circumferential Resection Margin

\begin{tabular}{|c|c|c|c|c|c|c|}
\hline \multicolumn{6}{|c|}{ Year of DSCA Registration } & \multirow{2}{*}{$\begin{array}{l}\chi^{2} \\
P \text { Value }\end{array}$} \\
\hline & 2009 & 2010 & 2011 & 2012 & 2013 & \\
\hline Male & $61.5 \%$ & $62.2 \%$ & $63.7 \%$ & $61.1 \%$ & $63.1 \%$ & .291 \\
\hline Age, y & & & & & & .311 \\
\hline $75+$ & $28.9 \%$ & $27.0 \%$ & $28.2 \%$ & $28.1 \%$ & $29.6 \%$ & \\
\hline ASA score & & & & & & .884 \\
\hline III & $16.9 \%$ & $16.8 \%$ & $17.6 \%$ & $17.8 \%$ & $17.3 \%$ & \\
\hline $\mathrm{BMI}, \mathrm{kg} / \mathrm{m}^{2}$ & & & & & & .005 \\
\hline $30+$ & $13.5 \%$ & $16.6 \%$ & $15.2 \%$ & $17.9 \%$ & $16.0 \%$ & \\
\hline Clinical T classification & & & & & & $<.001$ \\
\hline cT1 & $3.5 \%$ & $3.8 \%$ & $3.8 \%$ & $2.7 \%$ & $2.3 \%$ & \\
\hline сT2 & $19.2 \%$ & $23.3 \%$ & $23.3 \%$ & $24.0 \%$ & $21.2 \%$ & \\
\hline сT3 & $47.0 \%$ & $46.6 \%$ & $52.1 \%$ & $55.7 \%$ & $61.9 \%$ & \\
\hline cT4 & $9.9 \%$ & $8.7 \%$ & $7.9 \%$ & $8.6 \%$ & $9.1 \%$ & \\
\hline cTx/unknown & $20.4 \%$ & $17.5 \%$ & $12.9 \%$ & $8.9 \%$ & $5.5 \%$ & \\
\hline Distance from tumor to anus & & & & & & $<.001$ \\
\hline$\leq 5 \mathrm{~cm}$ & $35.8 \%$ & $32.3 \%$ & $34.9 \%$ & $33.3 \%$ & $36.2 \%$ & \\
\hline $6-10 \mathrm{~cm}$ & $35.6 \%$ & $39.0 \%$ & $38.5 \%$ & $38.9 \%$ & $39.0 \%$ & \\
\hline$>10 \mathrm{~cm}$ & $20.1 \%$ & $20.9 \%$ & $20.3 \%$ & $23.0 \%$ & $21.1 \%$ & \\
\hline Unknown & $8.5 \%$ & $7.8 \%$ & $6.2 \%$ & $4.8 \%$ & $3.7 \%$ & \\
\hline MRI & & & & & & $<.001$ \\
\hline Yes & $78.4 \%$ & $83.7 \%$ & $88.0 \%$ & $90.2 \%$ & $91.9 \%$ & \\
\hline Unknown & $11.3 \%$ & $6.7 \%$ & $3.2 \%$ & $1.7 \%$ & $1.8 \%$ & \\
\hline MDT & & & & & & $<.001$ \\
\hline Yes & $79.0 \%$ & $90.4 \%$ & $95.9 \%$ & $98.1 \%$ & $98.7 \%$ & \\
\hline Neoadjuvant therapy & & & & & & $<.001$ \\
\hline None & $21.3 \%$ & $16.9 \%$ & $14.1 \%$ & $18.2 \%$ & $18.6 \%$ & \\
\hline SCRT & $41.9 \%$ & $45.4 \%$ & $45.7 \%$ & $39.2 \%$ & $35.9 \%$ & \\
\hline SCRT-ds & $3.5 \%$ & $3.7 \%$ & $4.4 \%$ & $6.3 \%$ & $8.8 \%$ & \\
\hline CRT & $33.0 \%$ & $33.9 \%$ & $35.5 \%$ & $36.3 \%$ & $36.5 \%$ & \\
\hline Other & $0.3 \%$ & $0.1 \%$ & $0.3 \%$ & $0.0 \%$ & $0.2 \%$ & \\
\hline Procedure & & & & & & $<.001$ \\
\hline LAR & $58.0 \%$ & $61.5 \%$ & $65.8 \%$ & $70.5 \%$ & $68.9 \%$ & \\
\hline APR & $31.6 \%$ & $29.4 \%$ & $29.4 \%$ & $26.6 \%$ & $28.6 \%$ & \\
\hline Other/nonspecified & $10.4 \%$ & $9.2 \%$ & $4.8 \%$ & $2.8 \%$ & $2.6 \%$ & \\
\hline Approach & & & & & & $<.001$ \\
\hline Laparoscopic & $33.2 \%$ & $36.2 \%$ & $43.2 \%$ & $54.7 \%$ & $65.5 \%$ & \\
\hline Setting & & & & & & $<.001$ \\
\hline Nonelective & $5.4 \%$ & $2.6 \%$ & $1.7 \%$ & $2.3 \%$ & $1.5 \%$ & \\
\hline Pathologic T classification & & & & & & $<.001$ \\
\hline (у)рт1 & $7.4 \%$ & $7.1 \%$ & $8.3 \%$ & $8.5 \%$ & $8.8 \%$ & \\
\hline (у)рт2 & $28.5 \%$ & $32.0 \%$ & $33.9 \%$ & $32.8 \%$ & $33.3 \%$ & \\
\hline (у)рТ3 & $46.8 \%$ & $47.7 \%$ & $49.1 \%$ & $51.9 \%$ & $51.9 \%$ & \\
\hline (у)рT4 & $6.6 \%$ & $5.8 \%$ & $5.2 \%$ & $4.9 \%$ & $4.6 \%$ & \\
\hline (y)pTX/unknown & $10.6 \%$ & $7.3 \%$ & $3.5 \%$ & $2.0 \%$ & $1.5 \%$ & \\
\hline Pathologic N classification & & & & & & $<.001$ \\
\hline pNO & $58.7 \%$ & $61.5 \%$ & $61.0 \%$ & $62.6 \%$ & $63.0 \%$ & \\
\hline pN1 & $20.2 \%$ & $23.8 \%$ & $25.8 \%$ & $23.8 \%$ & $24.5 \%$ & \\
\hline pN2 & $12.8 \%$ & $11.6 \%$ & $10.4 \%$ & $12.6 \%$ & $11.8 \%$ & \\
\hline pNx/unknown & $8.3 \%$ & $3.0 \%$ & $2.7 \%$ & $1.1 \%$ & $0.8 \%$ & \\
\hline Metastatic disease & $8.3 \%$ & $7.8 \%$ & $7.5 \%$ & $8.2 \%$ & $7.5 \%$ & .806 \\
\hline
\end{tabular}

Abbreviations: APR, abdominoperineal resection; ASA, Association of Anesthesiologists; BMI, body mass index; CRM, circumferential resection margin; CRT, chemoradiotherapy; DSCA, Dutch Surgical Colorectal Audit; MDT, multidisciplinary team meeting; SCRT, short-course radiotherapy; SCRT-ds, short-course radiotherapy, delayed surgery; LAR, low anterior resection.

ing $(P<.001)$. A peak incidence occurred in the use of neoadjuvant therapy in 2011, and was still greater than $80 \%$ in 2013 . An increase was seen in the use of short-course radiotherapy with delayed
(>3 weeks) surgery (SCRT-ds) and chemoradiotherapy (CRT), both with a potential downsizing effect. The use of laparoscopic surgery doubled during this 5 -year period; from $33 \%$ in 2009 to $66 \%$ in 
$2013(P<.001)$. Nonelective resections decreased to $1.5 \%(P<.001)$.

\section{Reporting of CRM}

Figure 1 shows the mean percentage of patients with a reported CRM per year and displays the variation on this parameter between hospitals in 2009, 2011, and 2013. In 2009, the mean reported CRM rate was $52.7 \%$, which varied from $0 \%$ to $100 \%$ between individual hospitals. The mean percentage of patients with a reported CRM increased to $94.2 \%$ in 2013 and interhospital variation decreased (range, 33\%$100 \%$ in 2013). Baseline characteristics between patients with a reported and unreported CRM are displayed in Table 2, which shows that the percentage of patients without a reported $\mathrm{T}$ and $\mathrm{N}$ classification was higher among patients without a reported CRM than among patients with a reported CRM.

\section{CRM Involvement}

In 2009, the mean rate of CRM involvement was $14.2 \%$ in patients with a reported CRM (Table 3). In 2013, the mean percentage of CRM involvement was $5.6 \%$ in the $94 \%$ of patients with a reported CRM. Figure 2 shows the variation of CRM involvement among the Dutch hospitals in 2009, 2011, and 2013. The mean percentage of patients with an involved CRM was significantly lower in 2013 compared with 2009 $(P<.001)$. Furthermore, interhospital variation had decreased since the start of the DSCA (range, 0\%-90\% in 2009; range, $0 \%-22 \%$ in 2013). None of the hospitals were a negative outlier; however, because of low annual numbers of rectal cancer resections per hospital per year, confidence intervals are wide. Year of DSCA registration had a significant effect on CRM involvement in the linear-by-linear association test $(P=.005)$.

\section{Predictors of CRM Involvement}

Table 4 displays the univariable and multivariable analysis of potential predictors for CRM involvement, including the year of DSCA registration. In multivariable analysis, the year of DSCA registration remained a significant influence on CRM involvement, with an odds ratio of 0.47 for registration year 2013 compared with 2009. Together with the year of DSCA registration, clinical T classification, procedure, approach, setting, and pathologic $\mathrm{T}$ classification had a significant influence on CRM involvement. To consider the correlation in the multivariate model between clinical and pathologic $\mathrm{T}$ classification, we repeated the multivariable analy-

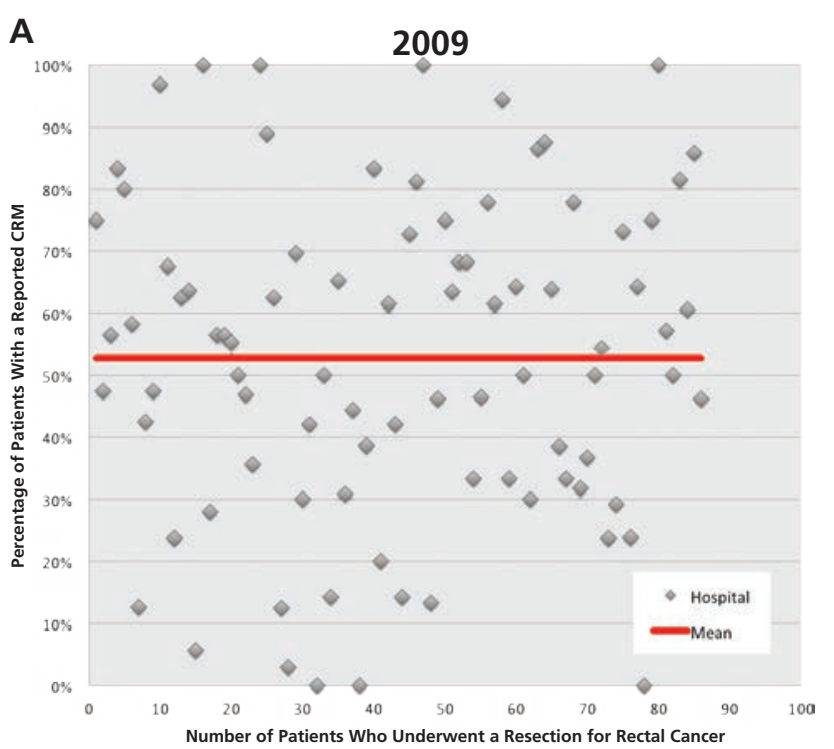

B
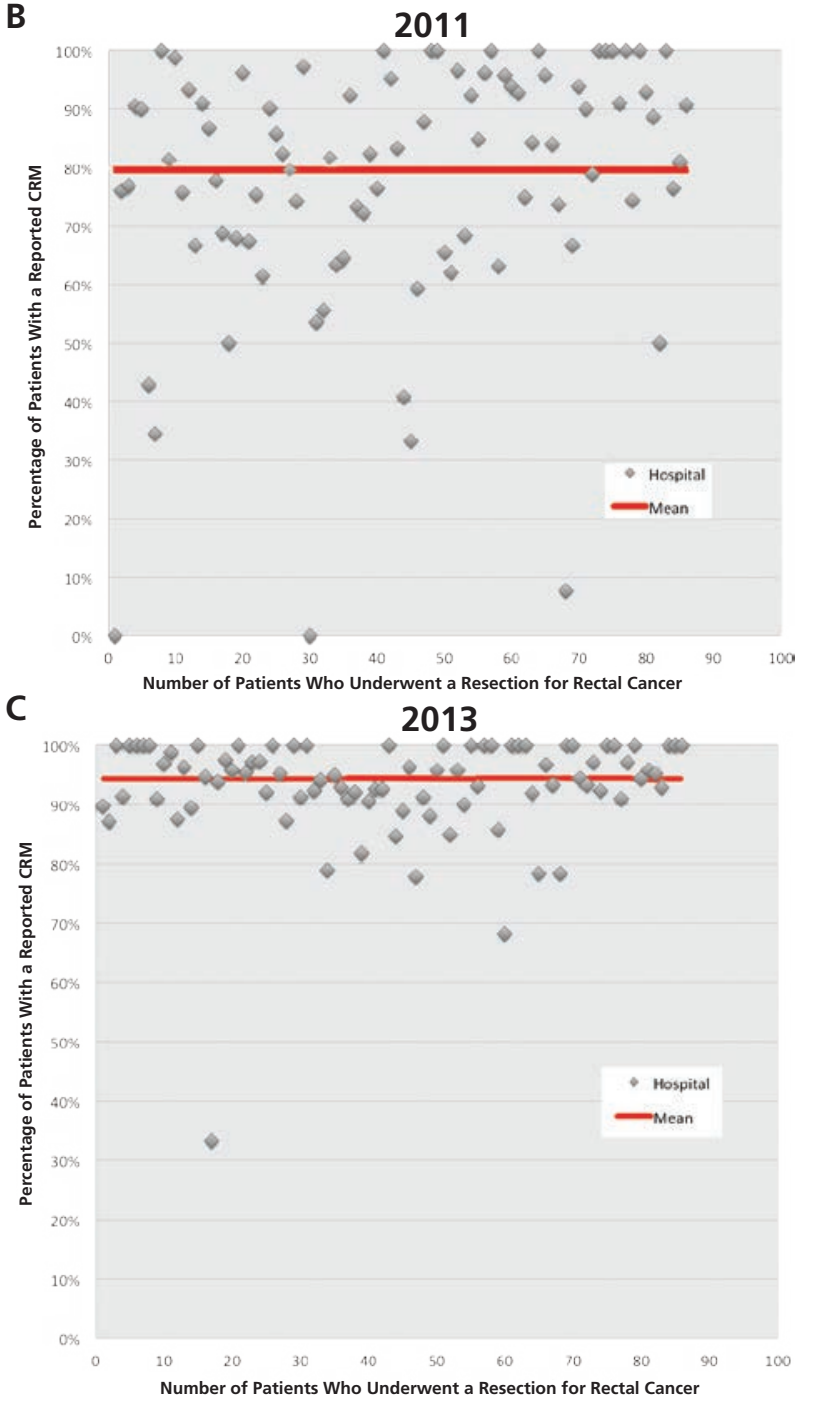

Figure 1 Scatterplots showing the mean percentage and hospital variation of patients with a reported circumferential resection margin (CRM) in (A) 2009, (B) 2011, and (C) 2013. 


\begin{tabular}{|lccc}
\hline \multicolumn{4}{c}{ Table 2 Baseline Characteristics of Tumors } \\
With and Without a Reported CRM
\end{tabular}

Abbreviations: APR, abdominoperineal resection; CRM, circumferential resection margin; CRT, chemoradiotherapy; LAR, low anterior resection; SCRT, short-course radiotherapy; SCRT-ds, short-course radiotherapy, delayed surgery.

sis without pathologic $\mathrm{T}$ classification; results, however, remained unchanged (data not shown).

\section{Discussion}

After the introduction of the DSCA as a quality assurance initiative in The Netherlands, a dramatic improvement has occurred in the percentage of pa-

\begin{tabular}{|c|c|c|c|c|c|}
\hline \multirow[b]{2}{*}{ Year } & \multirow{2}{*}{$\begin{array}{l}\text { Total }{ }^{a} \\
\mathrm{~N}\end{array}$} & \multicolumn{2}{|c|}{ Reported CRM } & \multicolumn{2}{|c|}{$\mathrm{CRM}^{\mathrm{b}}$} \\
\hline & & $\mathbf{n}$ & $\%$ & $\mathrm{n}$ & $\%$ \\
\hline 2009 & 2056 & 1084 & 52.7 & 154 & 14.2 \\
\hline 2010 & 2447 & 1531 & 62.6 & 185 & 12.1 \\
\hline 2011 & 2462 & 1956 & 79.4 & 177 & 9.0 \\
\hline 2012 & 2692 & 2480 & 92.1 & 197 & 7.9 \\
\hline 2013 & 2521 & 2375 & 94.2 & 134 & 5.6 \\
\hline
\end{tabular}

Abbreviation: CRM, circumferential resection margin. apatients who should have a reported CRM.

tients with a reported CRM in rectal cancer surgery. Alongside this improvement, there has been a major decrease of CRM involvement, which is known to have a significant effect on the long-term outcomes of patients with rectal cancer. Such substantial progress in the quality of rectal cancer care has not been observed since the introduction and standardization of the TME technique and the concomitant use of neoadjuvant therapy. ${ }^{3}$ Improvement in CRM reporting is almost exclusively attributable to the national audit, and the present multivariable analysis also suggests that the DSCA was a driving force behind the significant increase in tumor-free resection margins.

Population-based studies and other national audits on rectal cancer confirmed that the CRM, as an important measure for the quality of surgical resection, was often lacking in the pathology report. ${ }^{11-14}$ Swellengrebel et $\mathrm{a}^{15}$ performed a population study on the value of multidisciplinary team meetings in The Netherlands between 2006 and 2008, right before the start of the DSCA, and showed that only $61 \%$ of patients had a reported CRM. This is substantially lower than the $97 \%$ reported CRM rate in the Dutch TME trial (1996-1999), confirming again that a trial setting does not represent routine daily practice. But why was the standardized pathology reporting from the TME trial not implemented in The Netherlands? This is especially important to ask given the numerous publications from The Netherlands at that time showing that CRM is one of the most important outcome parameters in rectal cancer.,16-19 Apparently, confronting the individual hospitals with their data, benchmarking their outcomes, and making CRM reporting a quality indicator that is made available to external parties is what eventually does lead to practice changing. The present analysis 
Gietelink et al

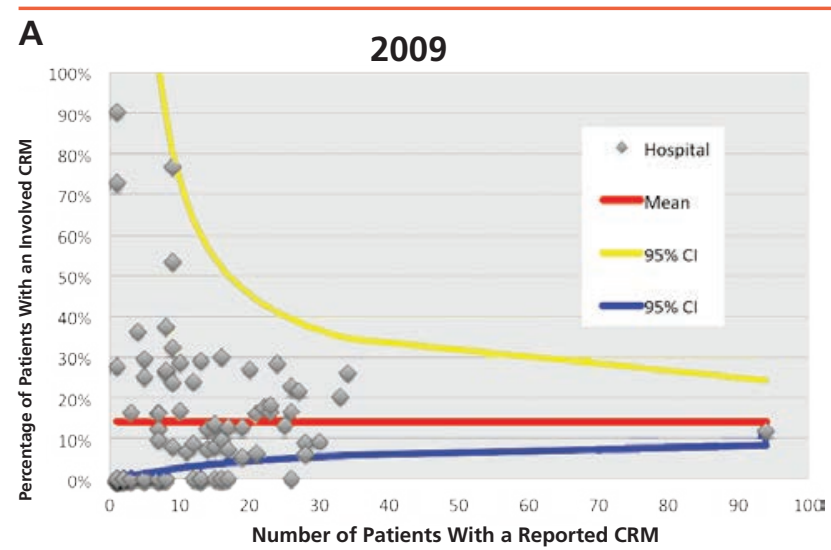

B

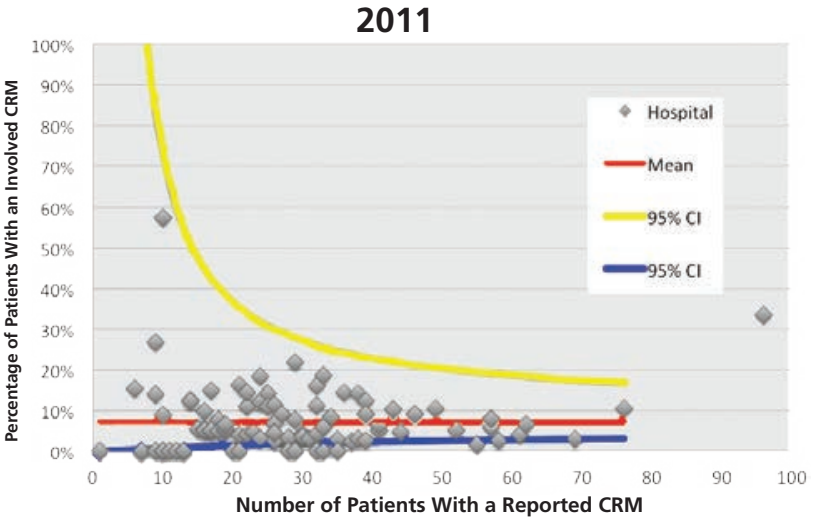

C

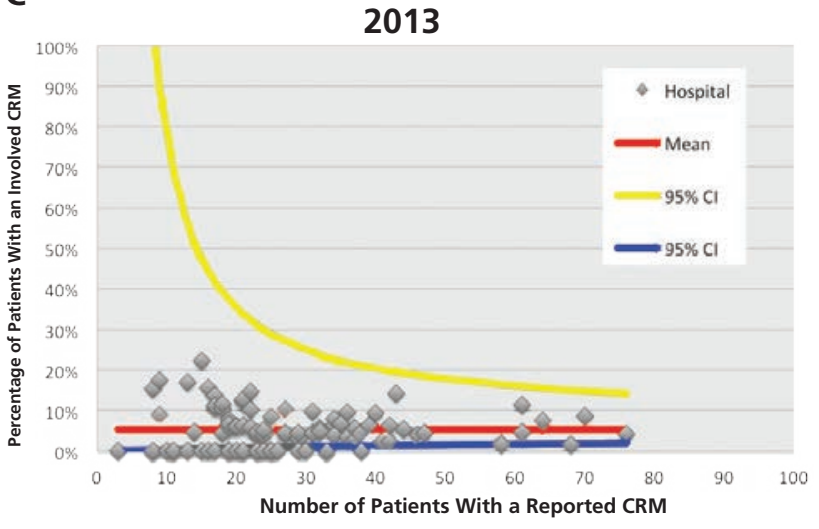

Figure 2 Funnelplot showing the case-mix-corrected percentage of patients with an involved circumferential resection margin (CRM) per hospital in (A) 2009, (B) 2011, and (C) 2013.

shows that quality indicators play an important role in identifying quality concerns and variation, and enable targeted quality improvement projects.

Other countries with a national audit on rectal cancer, such as the United Kingdom, also reported on CRM-related quality indicators. ${ }^{20} \mathrm{~A}$ decrease in CRM involvement has been observed by the $\mathrm{Na}$ tional Bowel Cancer Audit Programme (NBOCAP) in the United Kingdom, although only a minor im- provement in CRM reporting was found, with still more than $30 \%$ of patients without a reported CRM in 2013. Remarkably similar results as those observed in The Netherlands were found by a regional Quality Initiative in Canada in a population of 1.3 million inhabitants for whom colorectal cancer surgery is provided in 8 community hospitals and 3 teaching hospitals. ${ }^{21}$ During 2-yearly voluntary workshops, quality markers were selected by the participating surgeons, together with the commencement of improvement interventions, such as auditing and feedback, preoperative multidisciplinary consultation, and a system event-reporting system. In the period between 2006 and 2012, CRM reporting improved from $55 \%$ to $93 \%$ and CRM involvement decreased from $14 \%$ to $6 \%$. In the limitations of this study, the authors question the generalizability of their findings. Our study proves that almost identical improvements can be achieved by just auditing, even at a national level with more than 16 million inhabitants.

This positive effect of feedback on CRM involvement has been described previously. In the MRC CR07 trial, quality of the resection specimen was prospectively assessed and reported to the surgeons. As the study proceeded, the percentage of CRM involvement decreased significantly from $21 \%$ to $10 \% .{ }^{22}$ Evaluation of the TME specimen and assessment of the CRM by the pathologist provide direct feedback to the surgeon on the technical performance of the resection, and therefore they should be dedicated team members who participate in multidisciplinary meetings in which patients are discussed postoperatively. ${ }^{19}$ Furthermore, Quirke et $\mathrm{al}^{22}$ also pointed out the possible influence of the introduction of standard preoperative MDT meetings and local staging with MRI, which both could have led to the decreased percentage of CRM involvement in the MRC CR07 study. The DSCA included preoperative MRI and the discussion of patients in a preoperative MDT meeting as quality indicators, and improvements in both indicators have been observed (Table 1). Because both preoperative MRI and MDT meetings were already an obligatory part of the diagnostic pathway for patients with rectal cancer according to the Dutch national guidelines, the improvements can also be seen as a result of the DSCA. Both factors were significantly associated with CRM involvement in univariable analysis, but 


\begin{tabular}{|c|c|c|c|c|}
\hline \multirow[b]{3}{*}{ Variable (ref) } & \multirow{3}{*}{ 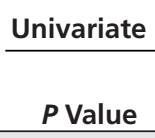 } & \multicolumn{3}{|c|}{ Multivariate } \\
\hline & & \multirow[b]{2}{*}{ OR } & \multicolumn{2}{|l|}{$\mathrm{Cl}$} \\
\hline & & & Lower & Upper \\
\hline Clinical T classification (cT1) & $<.001$ & & & \\
\hline cT2 & & 1.33 & 0.67 & 2.65 \\
\hline сT3 & & 1.21 & 0.62 & 2.36 \\
\hline cT4 & & 1.33 & 0.65 & 2.68 \\
\hline cTx & & 0.95 & 0.47 & 1.96 \\
\hline Distance from tumor to anus $(>10 \mathrm{~cm})$ & $<.001$ & & & \\
\hline$\leq 5 \mathrm{~cm}$ & & 1.16 & 0.90 & 1.51 \\
\hline $6-10 \mathrm{~cm}$ & & 0.95 & 0.76 & 1.18 \\
\hline Unknown & & 1.09 & 0.75 & 1.59 \\
\hline MRI (no) & .06 & & & \\
\hline Yes & & 1.04 & 0.80 & 1.35 \\
\hline MDT (no) & .055 & 0.96 & 0.68 & 1.36 \\
\hline \multicolumn{5}{|l|}{ Yes } \\
\hline Downsizing radiotherapy (no) & $<.001$ & & & \\
\hline Yes & & 1.15 & 0.96 & 1.37 \\
\hline Procedure (LAR) & $<.001$ & & & \\
\hline APR & & 1.49 & 1.21 & 1.84 \\
\hline Other/nonspecified & & 1.49 & 1.02 & 2.16 \\
\hline Approach (open) & $<.001$ & & & \\
\hline Laparoscopic & & 0.82 & 0.70 & 0.97 \\
\hline Setting (elective) & $<.001$ & & & \\
\hline Urgent & & 2.22 & 1.43 & 3.47 \\
\hline Pathologic T classification ((y)pT1) & $<.001$ & & & \\
\hline (у)pт2 & & 1.52 & 0.82 & 2.81 \\
\hline (у)рт3 & & 6.35 & 3.54 & 11.40 \\
\hline (у)рт4 & & 29.19 & 15.68 & 54.33 \\
\hline (y)pTx & & 2.43 & 1.00 & 5.90 \\
\hline Year of DSCA registration (2009) & $<.001$ & & & \\
\hline 2010 & & 0.97 & 0.75 & 1.25 \\
\hline 2011 & & 0.75 & 0.58 & 0.96 \\
\hline 2012 & & 0.67 & 0.52 & 0.86 \\
\hline 2013 & & 0.47 & 0.35 & 0.61 \\
\hline
\end{tabular}

Abbreviations: APR, abdominoperineal resection; ASA, Association of Anesthesiologists; CRM, circumferential resection margin; DSCA, Dutch Surgical Colorectal Audit; LAR, low anterior resection; MDT, multidisciplinary team meeting; OR, odds ratio.

lost their significance in multivariable analysis. Other changes during the study period that may have contributed to the decrease of CRM involvement in our study period are the increased use of down- staging radiotherapy regimens (SCRT-ds and CRT), which indeed were shown to be related to the risk of an involved CRM in univariable analysis, but not in multivariable analysis. The above-mentioned factors 
could also have slightly influenced CRM reporting. A multivariate analysis (data not shown), however, showed a significant and independent effect of the year of registration on CRM reporting, when the effect was corrected for all these factors. The positive impact of increased use of minimally invasive techniques on CRM involvement is difficult to interpret, because a meta-analysis of randomized controlled trials revealed no difference in CRM involvement between laparoscopic and open TME surgery. ${ }^{19}$ This finding could reflect the use of laparoscopic surgery by more specialized colorectal surgeons within more dedicated teams, but it might also be influenced by the inherent risk of selection bias within population studies. Although the influence of the approach on CRM involvement was analyzed in a multivariate model, there could be unmeasured factors that influenced the decision between open and laparoscopic resection.

No other important changes in the treatment of rectal cancer occurred in The Netherlands during the years examined by the present study. The multivariable analysis demonstrates the independent significant influence of the registration year on the risk of CRM involvement, which strenghtens the argument that the DSCA has been one of the leading factors in the major improvement of CRM involvement in The Netherlands in only a 5-year period.

The limitation of this study is that it remains difficult to estimate to what extent the audit has influenced the improved outcome of CRM reporting and involvement. Although we think we addressed the most important clinical changes, we cannot exclude the possibility of other clinical changes that could have influenced these improvements and are not captured in the DSCA database. Furthermore we cannot exclude some reporting bias. Table 1 shows a disproportionate increase of mid-rectal tumors and low anterior resection procedures, and some hospitals with low numbers of patients with a reported CRM might have reported relatively more patients with CRM involvement in the first registration years. However, this seems unlikely, because a population-based study from The Netherlands showed equal CRM involvement in that period. ${ }^{15}$ Furthermore, the 14\% CRM involvement at the start of the DSCA is even favorable if compared with the $16 \%$ CRM involvement in the Dutch TME trial, especially considering the fact that the audit also includes locally advanced rectal cancer. ${ }^{2}$

\section{Conclusions}

A marked improvement has occurred in the percentage of patients with a reported CRM since the start of the DSCA as a national quality assurance program. Furthermore, there has been a significant decrease of patients with CRM involvement, which contributes to a better prognosis for these patients. Few other interventions in the care of patients with rectal cancer have led to such magnitude of improvements in a relatively short period, and this shows the value of national auditing as a tool for quality improvement.

\section{Acknowledgments}

The authors would like to thank all of the surgeons, registrars, physician assistants, and administrative nurses who registered all the patients in the DSCA, as well as the Dutch Surgical Colorectal Cancer Audit group.

\section{References}

1. Weitz J, Koch M, Debus J, et al. Colorectal cancer. Lancet 2005;365:153 165.

2. van Gijn W, Marijnen CA, Nagtegaal ID, et al. Preoperative radiotherapy combined with total mesorectal excision for resectable rectal cancer: 12-year follow-up of the multicentre, randomised controlled TME trial Lancet Oncol 2011;12:575-582.

3. den Dulk M, Krijnen P, Marijnen CA, et al. Improved overall survival for patients with rectal cancer since 1990: the effects of TME surgery and preoperative radiotherapy. Eur J Cancer 2008;44:1710-1716.

4. Nagtegaal ID, Quirke P. What is the role for the circumferential margin in the modern treatment of rectal cancer? J Clin Oncol 2008;26:303-312.

5. Kapiteijn E, Kranenbarg EK, Steup WH, et al. Total mesorectal excision (TME) with or without preoperative radiotherapy in the treatment of primary rectal cancer. Prospective randomised trial with standard operative and histopathological techniques. Dutch ColoRectal Cancer Group. Eur J Surg 1999;165:410-420

6. Sebag-Montefiore D, Stephens RJ, Steele R, et al. Preoperative radiotherapy versus selective postoperative chemoradiotherapy in patient with rectal cancer (MRC CR07 and NCIC-CTG C016): a multicentre, randomised trial. Lancet 2009;373:811-820.

7. Van Leersum NJ, Snijders HS, Henneman D, et al. The Dutch Surgical Colorectal Audit. Eur J Surg Oncol 2013;39:1063-1070.

8. Annual Report 2013. The Dutch Surgical Colorectal Audit. Dutch Institute for Clinical Auditing Web site. Available at: http://clinicalaudit. $\mathrm{nl} /$ jaarrapportage/2013/archief/DICA\%20Jaarrapportage\%202013.pdf Accessed February 1, 2015.

9. Kolfschoten NE, Marang van de Mheen PJ, Gooiker GA, et al. Variation in case-mix between hospitals treating colorectal cancer patients in the Netherlands. Eur J Surg Oncol 2011;37:956-963.

10. Dutch national guidelines, colorectal cancer. Available at: http://www. oncoline.nl. Accessed January 1, 2015.

11. Bernstein TE, Endreseth BH, Romundstad P, Wibe A. Circumferential resection margin as a prognostic factor in rectal cancer. $\mathrm{Br} \mathrm{J}$ Surg 2009;96:1348-1357. 
Reduced Circumferential Resection Margin

12. National Bowel Cancer Audit Annual Report 2013. Available at: http://www.acpgbi.org.uk/content/uploads/Bowel-Cancer-Audit-2013 INTERACTIVE-PDF_01-07-13.pdf. Accessed February 1, 2015.

13. Demetter $P$, Vandendael $T$, Sempoux $C$, et al. Need for objective and reproducible criteria in histopathological assessment of total mesorectal excision specimens: lessons from a national improvement project. Colorectal Dis 2013;15:1351-1358.

14. Jorgren F, Johansson R, Damber L, Lindmark G. Risk factors of rectal cancer local recurrence: population-based survey and validation of the Swedish rectal cancer registry. Colorectal Dis 2010;12:977-986.

15. Swellengrebel HA, Peters EG, Cats A, et al. Multidisciplinary discussion and management of rectal cancer: a population-based study. World J Surg 2011;35:2125-2133.

16. Nagtegaal ID, Marijnen CA, Kranenbarg EK, et al. Circumferential margin involvement is still an important predictor of local recurrence in rectal carcinoma: not one millimeter but two millimeters is the limit. Am J Surg Pathol 2002;26:350-357.

17. Gosens MJ, Klaassen RA, Tan-Go I, et al. Circumferential margin involvement is the crucial prognostic factor after multimodality treatment in patients with locally advanced rectal carcinoma. Clin Cancer Res 2007;13(22 Pt 1):6617-6623.

18. den Dulk M, Collette L, van de Velde CJ, et al. Quality of surgery in T3-4 rectal cancer: involvement of circumferential resection margin not influenced by preoperative treatment. Results from EORTC trial 22921. Eur J Cancer 2007;43:1821-1828.

19. Nagtegaal ID, van Krieken JH. The role of pathologists in the quality control of diagnosis and treatment of rectal cancer-an overview. Eur J Cancer 2002;38:964-972.

20. National Bowel Cancer Audit Report 2014. Available at: http://www.hqip. org.uk/assets/NCAPOP-Library/NCAPOP-2014-15/nati-clin-audi-suppprog-bowe-canc-2014-rep1.pdf. Accessed February 1, 2015.

21. Simunovic M, Stephen W, Kelly S, et al. Quality improvement in colorectal cancer in local health integration network 4 (LHIN 4) project (QICC-L4): integrated knowledge translation in a large geographic region. Ann Surg Oncol 2013;20:4067-4072.

22. Quirke P, Steele R, Monson J, et al. Effect of the plane of surgery achieved on local recurrence in patients with operable rectal cancer: a prospective study using data from the MRC CR07 and NCIC-CTG CO16 randomised clinical trial. Lancet 2009;373:821-828.

\section{Earn up to 1.5 clock hours per webinar!}

These six live webinars will help case managers and medical directors learn more about the current state-of-the-art in oncology care. Attend and learn to manage patients with cancer based on evidence and according to the recommendations in the NCCN Clinical Practice Guidelines in Oncology (NCCN Guidelines ${ }^{\circledR}$ ). Webinar topics include:

- Updates in the Diagnosis and Treatment of Melanoma

- Challenges in Assessing and Using Biomarkers in Oncology Care

- Management of Cancer in Older Patients with Comorbidities

- Case Manager Techniques - Managing Symptoms and Reducing Complications

- Overview of Less Common and Complex Cancers (Part I)

- Overview of Less Common and Complex Cancers (Part II)

\section{Register at NCCN.org/events}

